\title{
Establishment of 2D Cell Cultures Derived From 3D MCF-7 Spheroids Displaying a Doxorubicin Resistant Profile
}

\author{
Ana S. Nunes, Elisabete C. Costa, Andreia S. Barros, Duarte de Melo-Diogo, \\ and Ilídio J. Correia*
}

In vitro 3D cancer spheroids generally exhibit a drug resistance profile similar to that found in solid tumors. Due to this property, these models are an appealing for anticancer compounds screening. Nevertheless, the techniques and methods aimed for drug discovery are mostly standardized for cells cultured in 2D. The development of 2D cell culture models displaying a drug resistant profile is required to mimic the in vivo tumors, while the equipment, techniques, and methodologies established for conventional 2D cell cultures can continue to be employed in compound screening. In this work, the response of 3D-derived MCF-7 cells subsequently cultured in 2D in medium supplemented with glutathione (GSH) (antioxidant agent found in high levels in breast cancer tissues and a promoter of cancer cells resistance) to Doxorubicin (DOX) is evaluated. These cells demonstrated a resistance toward DOX closer to that displayed by 3D spheroids, which is higher than that exhibited by standard 2D cell cultures. In fact, the $50 \%$ inhibitory concentration $\left(\mathrm{IC}_{50}\right)$ of DOX in 3D-derived MCF-7 cell cultures supplemented with GSH is about eight-times higher than that obtained for conventional 2D cell cultures (cultured without GSH), and is only about two-times lower than that attained for 3D MCF-7 spheroids (cultured without GSH). Further investigation revealed that this improved resistance of 3D-derived MCF-7 cells may result from their increased P-glycoprotein (P-gp) activity and reduced production of intracellular reactive oxygen species (ROS). anticancer drugs (mostly due to the upregulation of multidrug resistance proteins like drug efflux transporters [e.g., P-gp]), which highlights the importance of developing more effective therapeutics. ${ }^{[2,4,5]}$

The validation of new anticancer agents comprises several steps, including an exhaustive candidate selection during a preclinical stage. During this stage, different in vitro (cell cultures) and in in vivo (animals) assays are performed to determine the pharmacological properties of the drug formulations, as well as their therapeutic action. ${ }^{[2,6]}$ For this purpose, the performance of a number of drugs has been analyzed using 2D in vitro models due to their simplicity, reproducibility, and lowcost. $^{[7-11]}$ Still, these 2D in vitro models can only be used to investigate the direct effects of the drugs in the cells and do not take into consideration the role of the physiological 3D environment of the cells in drugs resistance. Therefore, the exclusive use of 2D in vitro models can lead to poor predictive results concerning drug's effectiveness. ${ }^{[2,13]}$ Having this in mind, 3D in vitro models, such as tumor spheroids (small cellular aggregates with a spherical-like shape), emerged in the early 70 s to serve as an intermediate model between standard 2D cell cultures and animal in vivo models. ${ }^{[1,14,15]}$ Unlike the $2 \mathrm{D}$ in vitro models, spheroids present a microenviron-

\section{Introduction}

Cancer is a leading cause of death in both developed and undeveloped countries. ${ }^{[1,2]}$ Among the treatments used in the clinic to treat this disease, chemotherapy is the most commonly used. $^{[3]}$ However, tumor cells can acquire resistance to

A. S. Nunes, E. C. Costa, A. S. Barros, D. de Melo-Diogo,

I. J. Correia

CICS-UBI - Health Sciences Research Centre

Universidade da Beira Interior

Avenida Infante D. Henrique, 6200-506 Covilhã, Portugal

E-mail: icorreia@fcsaude.ubi.pt

I. J. Correia

CIEPQF - Departamento de Engenharia Química

Universidade de Coimbra

Rua Sílvio Lima, Polo II, 3030-790 Coimbra, Portugal

The ORCID identification number(s) for the author(s) of this article can be found under https://doi.org/10.1002/biot.201800268.

DOI: 10.1002/biot.201800268 ment and cellular organization that grant them a higher resistance to anticancer drugs. ${ }^{[16-22]}$ Despite of the potential of spheroids for compounds screening and the emergence of technologies for highthroughput drug screening (HTS) in spheroids, these in vitro models still present some challenges and limitations associated (reviewed in refs. [23-27]). For instance, there is an urgent need to optimize some of the spheroids production techniques in order to attain these microtissues under highly reproducible conditions. This is particularly important since spheroids with different attributes (sizes and/or shapes) may be a source of results' variability. ${ }^{[28-31]}$ Another concern about the use of spheroids is related to the lack of compatibility of the majority of the equipment used for the analysis of 2D cell cultures with these 3D models and also to the higher costs associated with the technologies developed for the analysis of 3D cell cultures. ${ }^{[14,27,32]}$ In particular, some fluorescence microscopes (e.g., confocal analyzing modalities) are not optimal for the imaging of large $(>100 \mu \mathrm{m}$ in diameter) and 
dense spheroids due to the light scattering, light absorption and poor light penetration associated to prolonged imaging acquisition times. ${ }^{[24,25,27]}$

On the other hand, researchers are developing drug resistant 2D cell cultures. ${ }^{[7,33-40]}$ These models show a drug resistance profile more alike to that found in in vivo tumors and can be analyzed through standardized assays and equipment used for conventional 2D cell cultures. Recently, Koshkin et al. demonstrated that 3Dderived MCF-7 cells (cells obtained from 3D spheroids disaggregation) are able to preserve their 3D-phenotype when cultured in $2 \mathrm{D} \cdot{ }^{[7]}$ Additionally, this phenotype was maintained for longer periods (up to $96 \mathrm{~h}$ ) by culturing the 3D-derived cells in medium supplemented with $5 \mathrm{mM}$ of glutathione (GSH; reducing and antioxidant agent found in high levels in various cancer [e.g., breast cancer] and an influencer of cancer cells resistance). ${ }^{[7,41-49]}$ However, so far, the applicability of the 3D-derived cells for evaluating a drug response has not been investigated. Furthermore, the effect of drugs in 3D-derived cells in 2D has not yet been compared to that occurring in conventional 2D models and 3D spheroids. Therefore, this work intended to investigate the effect of Doxorubicin (DOX; an anthracycline widely used in treatment of several cancers, whose therapeutic effect is broadly reduced by the cells resistance ${ }^{[50,51]}$ ) in 3D-derived MCF-7 cells (cultured in presence and absence of GSH) and compare it to that observed in MCF-7 cells cultured in 2D and as 3D spheroids. Then, the possible mechanisms that prompted the increased resistance to DOX of 3Dderived cells were investigated, namely the P-gp activity and ROS intracellular levels.

\section{Experimental Section}

\subsection{Materials}

Estrogen-dependent human breast adenocarcinoma (MCF-7) cells were acquired from ATCC (Middlesex, UK). Cell culture plates and T-flasks were obtained from Thermo Fisher Scientific (Porto, Portugal). 2',7'-dichlorofluorescein diacetate ( $\mathrm{H}_{2}$ DCFDA), Dulbecco's Modified Eagle's medium F-12 (DMEM-F12), ethylenediaminetetraacetic acid (EDTA), gentamicin, L-glutathione (GSH), paraformaldehyde (PFA), phosphate-buffered saline solution (PBS), resazurin, rhodamine 123 (Rho 123), streptomycin, and trypsin were bought from SigmaAldrich (Sintra, Portugal). Agarose was obtained from Grisp (Porto, Portugal). Fetal bovine serum (FBS) was purchased from Biochrom AG (Berlin, Germany). DOX was obtained from Carbosynth (Berkshire, UK). Cell imaging plates were acquired from Ibidi $\mathrm{GmbH}$ (Ibidi). The store solution of DOX was prepared in Methanol gotten from VWR International (Portugal).

\subsection{Methods}

\subsubsection{Cells Maintenance and 3D MCF-7 Spheroids Formation}

MCF-7 cells were cultured in DMEM-F12 supplemented with FBS $(10 \%[v / v])$ and streptomycin and gentamycin $(1 \%[v / v])$ in $75 \mathrm{~cm}^{2}$ T-flasks. Cells were incubated in a humidified atmosphere at $37^{\circ} \mathrm{C}$ and $5 \% \mathrm{CO}_{2} \cdot{ }^{[52]}$ For spheroids formation, agarose structures with spherical microwells were obtained by using a micro-mold (3D Petri Dish, Microtissues Inc., Providence RI, USA) and then used to promote cells self-assembly, as previously described by our group. ${ }^{[53]}$ These agarose structures were placed in cell culture plates (12-wells) and sterilized by UV radiation during $60 \mathrm{~min}$. Afterwards, cells were seeded in the agarose structures $\left(1 \times 10^{6}\right.$ cells/agarose structure). After some period of time, the MCF-7 cells aggregate spontaneously, allowing the obtention of 81 spheroids per agarose structure. These spheroids were maintained in DMEM-F12 (FBS 10\% [v/v] and streptomycin and gentamycin $1 \%[\mathrm{v} / \mathrm{v}])$ inside an incubator with a humidified atmosphere $\left(37^{\circ} \mathrm{C}, 5 \% \mathrm{CO}_{2}\right)$. The culture medium of the spheroids was exchanged every 2 days. The spheroids used in this study were allowed to grow for 10 days and they displayed a mean diameter of $694.07 \pm 62.18 \mu \mathrm{m}$ (analysis performed by using ImageJ software [National Institutes of Health], as previously described in our group ${ }^{[54,55]}$.

\subsubsection{Screening of DOX Effect on MCF-7 Cells Cultured in $2 D$}

MCF-7 cells (12400 cells/well) were seeded in 96-well culture plates and then incubated for $24 \mathrm{~h}$ with cell culture medium with or without GSH $(5 \mathrm{mM})$ supplementation. ${ }^{[7]}$ Afterwards, the medium was removed and cells were incubated with fresh cell culture medium containing different concentrations of DOX $(0.1-200 \mu \mathrm{M})$. After $24 \mathrm{~h}$, the culture medium was replaced by a fresh one containing resazurin $(10 \%[\mathrm{v} / \mathrm{v}])$ for $4 \mathrm{~h}\left(37^{\circ} \mathrm{C}, 5 \%\right.$ $\mathrm{CO}_{2}$ ). Then, MCF-7 cells viability was assessed by analyzing the fluorescence of resorufin $\left(\lambda_{\mathrm{ex}} / \lambda_{\mathrm{em}}=560 / 590 \mathrm{~nm}\right)$ in a Spectramax Gemini EM spectroflorometer (Molecular Devices LLC, CA, USA). Cells solely incubated with culture medium were used as the negative control $\left(\mathrm{K}^{-}\right)$.

Subsequently, the drugs' dose-response curves were traced in order to determine the DOX 20,50, and $80 \%$ inhibitory concentrations $\left(\mathrm{IC}_{20}, \mathrm{IC}_{50}\right.$, and $\mathrm{IC}_{80}$, respectively) using OriginLab software (trial version, OriginPro, OriginLab Corporation, MA, USA)..$^{[56,57]}$

\subsubsection{Screening of DOX Effect in MCF-7 Cells Cultured in $2.5 D$}

3D MCF-7 spheroids were disaggregated by using $0.25 \%$ trypsin (1:250) and EDTA $0.1 \%(\mathrm{w} / \mathrm{v})$. Afterwards, the 3D-derived cells were seeded in 96-well culture plates at a density of 12400 cells/well and incubated for $24 \mathrm{~h}$ with fresh culture medium with or without GSH (5 mM) supplementation. Subsequently, cells were incubated with culture medium containing DOX for $24 \mathrm{~h}(1-200 \mu \mathrm{M})$. Cells' viability and the DOX inhibitory concentrations were determined as described in Section 2.2.2.

\subsubsection{Screening of DOX Effect on 3D MCF-7 Spheroids}

3D MCF-7 spheroids were incubated for $24 \mathrm{~h}$ with fresh culture medium containing DOX $(25-200 \mu \mathrm{M})$. For each condition, a total of 45 spheroids were used (total of five wells, each well with 
nine spheroids). After $24 \mathrm{~h}$, MCF-7 cells' viability and the DOX inhibitory concentrations were determined as described above in Section 2.2.2.

The effect of DOX on 3D MCF-7 spheroids was also monitored by acquiring optical microscopy images (Olympus CX41 inverted optical microscope equipped with an Olympus SP-500 UZ digital camera) and by measuring the spheroids diameter (this analysis was performed by using ImageJ software (National Institutes of Health), as previously described in our group (see for further details Figure S1, Supporting Information). ${ }^{[54,55]}$

\subsubsection{Analysis of P-gp Activity Through Rho 123 Efflux Assay}

The Rho 123 efflux assay was performed according to a protocol previously reported in the literature with slight modifications. ${ }^{[58]}$ In brief, MCF-7 cells (obtained from 2D cell cultures or 3Dderived) were cultured in 96-well culture plates at a density of 12400 cells per well and incubated for $24 \mathrm{~h}$ with fresh medium (with or without GSH $5 \mathrm{mM}$ ). Then, the medium was replaced with fresh medium containing Rho $123(8 \mu \mathrm{M})$. After MCF-7 cells' incubation with the probe during $1 \mathrm{~h}$, the medium containing the probe was removed and fresh medium was added to the wells. Then, the fluorescence of the medium in the wells (that contains the Rho 123 expelled from the cells through the Pgp) was measured at 2,8 , and $24 \mathrm{~h}\left(\lambda_{\mathrm{ex}} / \lambda_{\mathrm{em}}=507 / 525 \mathrm{~nm}\right)$ on a Spectramax Gemini EM spectrofluorometer (Molecular Devices LLC). For comparative purposes, the obtained fluorescence intensity values were normalized with the fluorescence intensity of the initial Rho 123 solution administrated to the cells.

\subsubsection{Rho 123 and DOX Accumulation in MCF-7 Cells}

The analysis of the Rho 123 and DOX accumulation in the cells of the different in vitro models (2D cell cultures and 3D-derived cells) was performed by adapting protocols previously described elsewhere. ${ }^{[58-61]}$ In brief, MCF-7 cells (obtained from 2D cell cultures or 3D-derived) were cultured in $\mu$-slide eight-well imaging plates (Ibidi GmbH, Munich, Germany) at a density of 12400 cells/ well in culture medium with or without GSH supplementation $(5 \mathrm{mM})$. After $24 \mathrm{~h}$, the medium was replaced with fresh medium containing Rho $123(8 \mu \mathrm{M})$ or DOX $(9 \mu \mathrm{M})$ for $1 \mathrm{~h}$. Then, cells were incubated with fresh medium during 8 and/or $24 \mathrm{~h}$. After this period, the medium in the wells was removed, cells were chemically fixed (using PFA 4\% during $15 \mathrm{~min}$ ) and washed with PBS. Afterwards, to determine the accumulation of Rho 123 and DOX inside the MCF-7 cells, imaging experiments were performed by using a Zeiss LSM 710 confocal microscope (Carl Zeiss AG, Oberkochen, Germany) and processed in Carl Zeiss software ZEN 2 software (the CLSM images were equally digitally enhanced). Rho 123 and DOX were visualized by using $\lambda_{\text {ex }} /$ $\lambda_{\mathrm{em}}=514 / 519-650$ and $\lambda_{\mathrm{ex}} / \lambda_{\mathrm{em}}=488 / 535-674 \mathrm{~nm}$, respectively.

\subsubsection{Analysis of the ROS Levels in MCF-7 Cells Through $\mathrm{H}_{2}$ DCFDA Assay}

Intracellular levels of ROS in MCF-7 cells were analyzed by using $\mathrm{H}_{2}$ DCFDA (a non-fluorescent compound that is converted to the highly fluorescent 2',7'-dichlorofluorescein (DCF) in the presence of ROS), as previously described in literature. ${ }^{[62]}$ In brief, MCF-7 cells (obtained from 2D cell cultures or 3D-derived) at a density of 12400 cells/well were cultured during $24 \mathrm{~h}$ in $\mu$-slide eight-well imaging plates (Ibidi $\mathrm{GmbH}$ ) in cell culture medium with or without GSH supplementation $(5 \mathrm{mM})$. Then, cells were incubated during $30 \mathrm{~min}$ with hydrogen peroxide $\left(\mathrm{H}_{2} \mathrm{O}_{2} ; 0.3 \%\right.$ $[\mathrm{v} / \mathrm{v}])$. Afterwards, cells were washed with PBS and then incubated with $10 \mu \mathrm{M}$ of a $\mathrm{H}_{2}$ DCFDA in PBS for $1 \mathrm{~h}$. Lastly, the ROS levels in the cells were indirectly observed by imaging the DCF fluorescence using a Zeiss LSM 710 confocal microscope (Carl Zeiss AG) and using a $\lambda_{\text {ex }}$ of $488 \mathrm{~nm}$ and a $\lambda_{\mathrm{em}}$ of 493-599 $\mathrm{nm}$. The acquired images were processed in Carl Zeiss software ZEN 2 software and all the images were equally digitally enhanced. The DCF fluorescence intensity was determined by using ImageJ software (National Institutes of Health), as previously described elsewhere. ${ }^{[62-64]}$ In brief, the integrated density and the area of the CLSM image were measured for each CLSM image, as well as the mean fluorescence of the background (region without fluorescence). Then, the Corrected Total Cell Fluorescence (CTCF) was calculated according to Equation (1):

$$
\begin{aligned}
\mathrm{CTCF}= & \text { integrated density }-(\text { area }) \\
& \times \text { mean fluorescence of background }
\end{aligned}
$$

\subsubsection{Statistical Analysis}

Data were expressed as mean values \pm standard deviation (S.D.). The statistical analysis was performed by using one-way ANOVA test. A $P$-value lower than $0.05\left({ }^{*} P<0.05\right)$ was considered statistically significant. Data analysis was performed in GraphPad Prism v.6.0 software (Trial version, GraphPad Software, CA, USA).

\section{Results and Discussion}

2D cell cultures exhibiting resistance to anticancer drugs are promising models for compounds screening. Furthermore, resistant $2 \mathrm{D}$ cell cultures can be analyzed by conventional and standardized techniques/methodologies. The most commonly used breast cancer resistant 2D cell culture model is the MCF-7/ ADR cells. ${ }^{[36,65,66]}$ These cells are generally obtained by maintaining MCF-7 cells in culture medium supplemented with DOX for long periods of time. ${ }^{[3,34,36]}$ For instance, Desrini et al. obtained Doxorubicin resistant MCF-7 cell by exposing parental MCF-7 cells to DOX twice a week for a period of 25 days. ${ }^{[36]}$ Optionally, resistant MCF-7 cells can also be obtained by exposing them to hypoxic cycles (e.g., $<1 \%$ oxygen), ${ }^{[37,38]}$ since the hypoxia triggers the activation of a plethora of molecular pathways involved in cancer cells' resistance (reviewed in refs. [37,39,40]). As an example, Hamdan and Zihlif obtained MCF-7 cells resistant to DOX by subjecting the cells to hypoxia for $8 \mathrm{~h}$, repeating this process three times a week. ${ }^{[37]}$ However, these procedures can be expensive, timeconsuming and may require specific equipment (e.g., anaerobic 
atmosphere generating system) to maintain the cell culture under certain conditions. ${ }^{[67-70]}$ Therefore, there is an urgent need to develop new resistant $2 \mathrm{D}$ cell culture models that can be attained using inexpensive and simple processes, and that at the same time, display a drug-resistant profile similar to that found in tumor spheroids and in in vivo solid tumors.

In this study, a resistant 2D cell culture model of breast cancer (termed as $2.5 \mathrm{D}[+\mathrm{GSH}] \mathrm{MCF}-7$ cell culture) was obtained by a simple method that takes less than 2 weeks (Figure 1). This model was produced by culturing in 2D the MCF-7 cells obtained from 10 days-old 3D spheroids. The reasoning for this approach lays in the fact that several reports have demonstrated that 3D-derived cells present different properties from their equivalents cultured only in 2D. ${ }^{[7,71]}$ Furthermore, 3D-derived cells can also maintain their 3D phenotype upon spheroids disassociation (e.g., proliferation rate, drug expelling capacity) $\cdot{ }^{[7,71]}$ Herein, the 3D-derived MCF-7 cells were cultured in medium supplemented with GSH $(5 \mathrm{mM})$ since GSH: 1) is present in high concentrations in breast cancer tissues (in comparison to disease-free breast tissue); ${ }^{[49,72]} 2$ ) influences cells' proliferation and death; ${ }^{[73]} 3$ ) influences cells' resistance to therapeutics and radiation; ${ }^{[43-48,73]}$ and 4) can maintain for long periods of time the 3D phenotype of 3D-derived cells (up to $96 \mathrm{~h}$ ). ${ }^{[7]}$ Furthermore, the effect of DOX on the viability of $2.5 \mathrm{D}(+\mathrm{GSH})$ MCF-7 cells was determined and compared with that occurring in conventional 2D cell cultures (2D[-GSH] MCF-7 cells) and 3D MCF-7 spheroids. The mechanisms that may be involved in 2.5D $(+\mathrm{GSH})$ MCF-7 cells' resistance to DOX were also investigated.

\subsection{D, 2.5D, and 3D Breast Cancer Cell Cultures Response to Doxorubicin}

The effect of DOX in the viability of traditional 2D cell cultures (2D $[-$ GSH] MCF-7 cells) and 2.5D(+GSH) MCF-7 cell cultures was first investigated (Figure 2A,B; Table S1-S3, Supporting Information). Then, DOX-response curves were obtained in order determine the drug concentrations required to reduce cells' viability by 20,50 , and $80 \%\left(\mathrm{IC}_{20}, \mathrm{IC}_{50}, \mathrm{IC}_{80}\right)$. It was verified that $2.5 \mathrm{D}(+\mathrm{GSH}) \mathrm{MCF}-7$ cells were less affected by DOX when compared to $2 \mathrm{D}$ MCF-7 cells $\left(\mathrm{IC}_{20}=37.49 \mu \mathrm{M}\right.$; $\mathrm{IC}_{50}=68.68 \mu \mathrm{M} ; \mathrm{IC}_{80}=125.83 \mu \mathrm{M}$ vs. $\mathrm{IC}_{20}=3.14 \mu \mathrm{M} ; \mathrm{IC}_{50}$ $\left.=9.04 \mu \mathrm{M} ; \mathrm{IC}_{80}=26.03 \mu \mathrm{M}\right)$. In fact, the inhibitory concentrations revealed that the $\mathrm{IC}_{50}$ of DOX in $2.5 \mathrm{D}(+\mathrm{GSH}) \mathrm{MCF}-7$ cells was eightfold higher than the $\mathrm{IC}_{50}$ value obtained for the traditional 2D cell cultures (2D $-\mathrm{GSH}] \mathrm{MCF}-7$ cells). The higher resistance of $2.5 \mathrm{D}(+\mathrm{GSH})$ MCF-7 cells to DOX $(26.03 \mu \mathrm{M})$ was maintained up to $48 \mathrm{~h}$ of cultures' establishment (Figure S2, Supporting Information). The resistance to DOX displayed by $2.5 \mathrm{D}(+\mathrm{GSH}) \mathrm{MCF}-7$ cells is dependent on the GSH supplementation and on the 3D-derivation of these cells, while the 2D cell cultures sensibility to DOX was not significantly influenced by the GSH (Figure 2E). On the other hand, 3D-derived cells without GSH supplementation (2.5D[-GSH] cells) could display (at low doses of DOX [3.14 $\mu \mathrm{M}]$ ) some resistance to the effect of DOX. In stark contrast, $2.5 \mathrm{D}(+\mathrm{GSH})$ cells were less affected by DOX (at various concentrations of DOX [ 9.04 and $26.03 \mu \mathrm{M}]$ ), thereby confirming the improved DOX resistance profile displayed by this model.

To compare the level of resistance of the $2.5 \mathrm{D}(+\mathrm{GSH})$ to that displayed by 3D cell cultures, the effect of the DOX in 3D MCF-7 spheroids and its drug-response curves were also determined (Figure 2C). As expected, DOX induced a decrease on the spheroids' size (Figure S3, Supporting Information). ${ }^{[74,75]}$ The $\mathrm{IC}_{20}, \mathrm{IC}_{50}$, and $\mathrm{IC}_{80}$ of $\mathrm{DOX}$ in the $3 \mathrm{D}$ spheroids were determined to be $73.96,110.09$, and $163.97 \mu \mathrm{M}$, respectively (Figure 2C). Spheroids are more resistant to the effect of DOX when compared to $2.5 \mathrm{D}(+\mathrm{GSH})$ cells. This result was expected since spheroids' resistance to drugs is influenced by several factors (reviewed in detail in refs. [6,76,77]). As example, spheroids often demonstrate increased expression of ECM proteins (e.g., collagen, fibronectin) that can influence cancer cells' resistance to different therapeutics, such as DOX. ${ }^{[78-80]}$

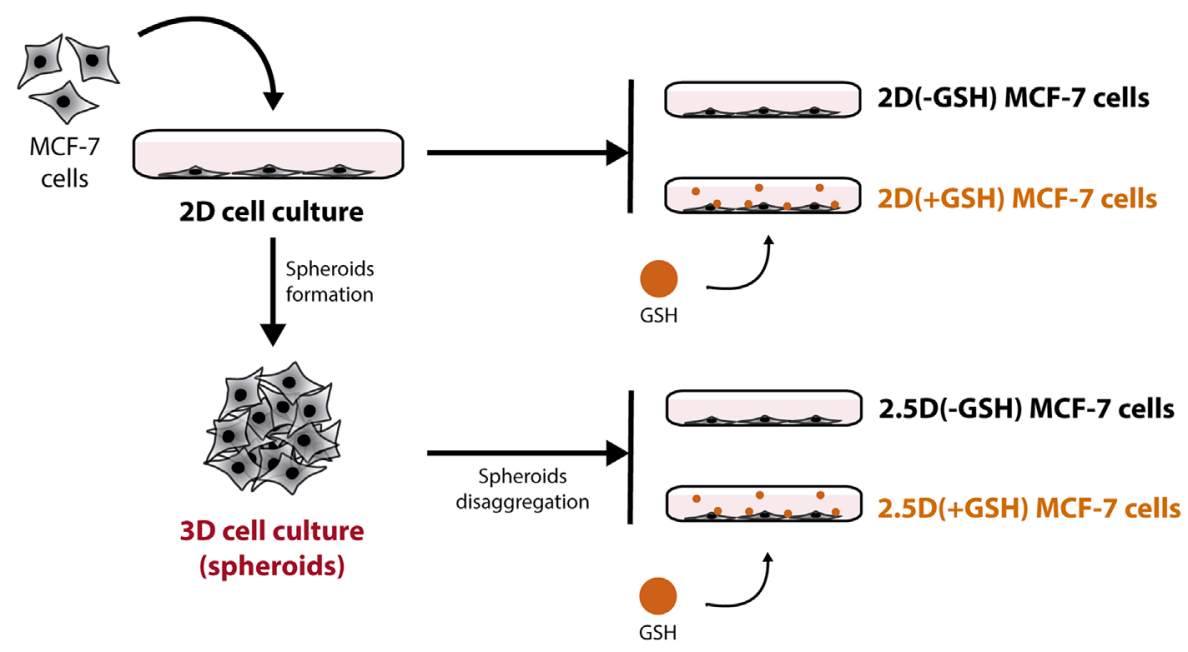

Figure 1. Schematic illustration of the MCF-7 cell cultures used in this work. During the study, it was used $2 \mathrm{D}(-\mathrm{GSH}) \mathrm{cultures}$ (traditional $2 \mathrm{D}$ cell cultures that grow in absence of $\mathrm{GSH}) ; 2 \mathrm{D}(+\mathrm{GSH})$ cultures (traditional 2D cell cultures that grow in presence of GSH); $2.5 \mathrm{D}(-\mathrm{GSH}) \mathrm{cultures}(3 \mathrm{D}$ derived cell cultures that grow in absence of $G S H) ; 2.5 \mathrm{D}(+\mathrm{GSH})$ cultures (3D-derived cell cultures that grow in presence of $\mathrm{GSH}$ ); and 3D spheroids. 

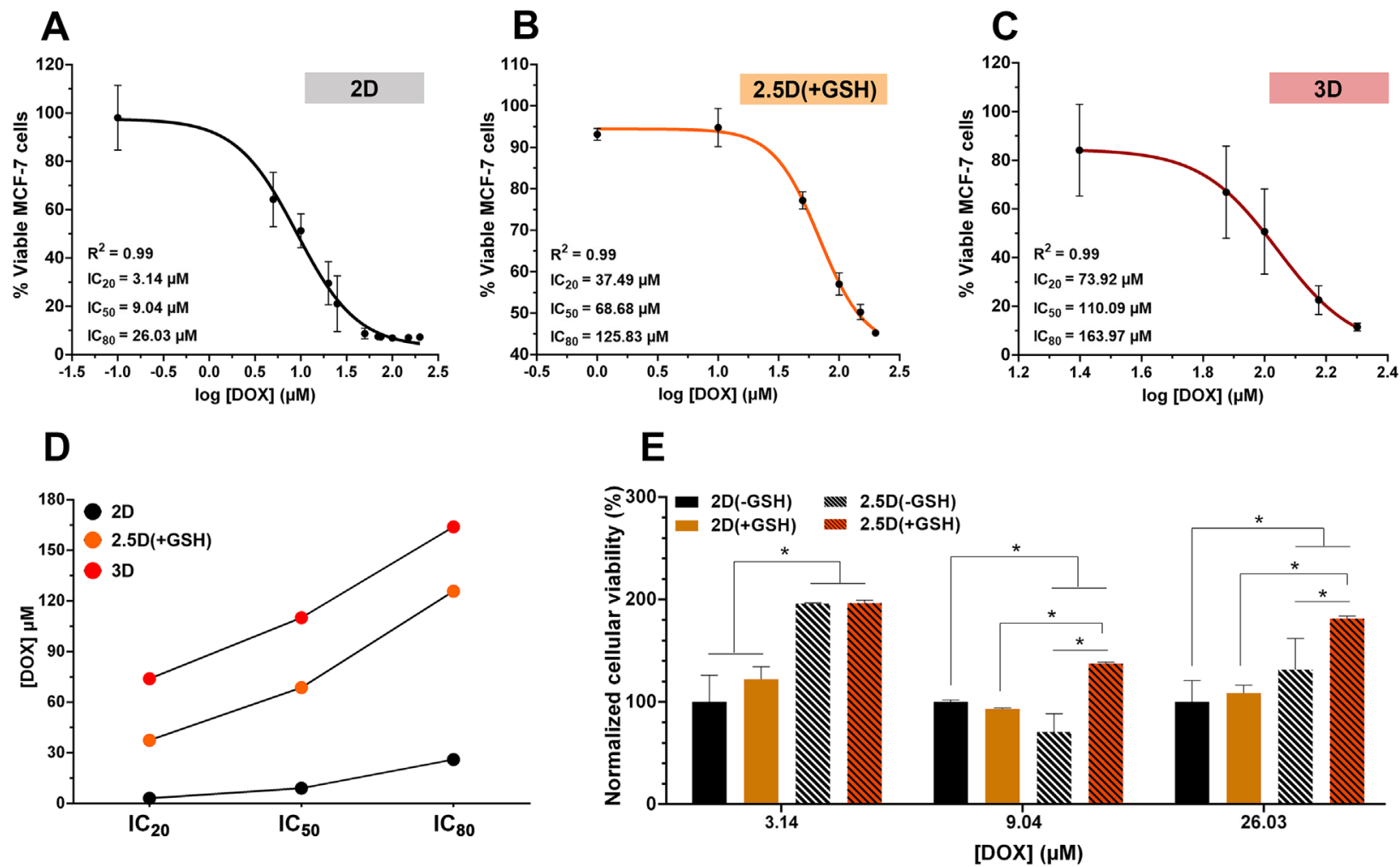

Figure 2. Evaluation of the DOX effect on the cellular viability of $2 \mathrm{D}, 2.5 \mathrm{D}$, and $3 \mathrm{D}$ MCF-7 cell cultures. Dose-response curves of $2 \mathrm{D}(-\mathrm{GSH})$ (A), 2.5D $(+\mathrm{GSH})(\mathrm{B})$, and 3D (C) MCF-7 cell cultures to DOX. Comparison of 20, 50, and $80 \%$ inhibitory concentrations of DOX $\left(\mathrm{IC}_{20}, \mathrm{IC}_{50}\right.$, and IC $\left.\mathrm{C}_{80}\right)$ in $2 \mathrm{D}(-\mathrm{GSH}), 2.5 \mathrm{D}(+\mathrm{GSH})$, and 3D MCF-7 cell cultures $(\mathrm{D})$. Cell viability of the different models after the administrations of several concentrations of DOX $(3.14,9.04$, and $26.04 \mu \mathrm{M})$ during $24 \mathrm{~h}$ (values were normalized toward the cell viability of $2 \mathrm{D}[-\mathrm{GSH}]$ cells which was considered the traditional cell culture model) (E); data are presented as mean \pm S.D. $(n=5) ;{ }^{*} P<0.05$.

However, 2.5D(+GSH) cells' DOX resistance profile is closer to that displayed by 3D spheroids when compared to conventional 2D models (Figure 2D). Together, these results confirm that the 2D cultures of MCF-7 cells derived from 3D spheroids cultured in the presence of GSH are an alternative in vitro model of DOX resistant breast cancer cells.

\subsection{Characterization of 2.5D $(+\mathrm{GSH})$ Breast Cancer Cell Culture Resistance Mechanisms Toward DOX}

High expression of efflux pumps is often associated with the increased resistance displayed by cancer cells to different drugs. ${ }^{[7,81]}$ One of the mechanisms potentially contributing to the resistance exhibited by cancer cells to DOX, involves the upregulation of P-gp expression (proteins that mediates DOX transport from cells). ${ }^{[7,81]}$ Various studies have demonstrated that GSH can affect the expression of this multidrug resistance (MDR) transporter, ${ }^{[4,47,48]}$ and it has been found that increased intracellular GSH or GSH related enzymes have been associated with MDR. ${ }^{[47,82]}$ Hong et al. observed that the treatment of cells with Buthionine Sulfoximine (BSO; an inhibitor of $\gamma$-Glutamylcysteine synthetase $[\gamma$-GCS], an enzyme that is responsible for GSH synthesis), decreases the levels of GSH in the cells and induces the down-regulation of the P-gp expression. ${ }^{[4]}$ Therefore, the increased DOX resistance displayed by $2.5 \mathrm{D}(+\mathrm{GSH})$ cells may be mediated by an up-regulation of the P-gp function due to the increase levels of GSH in these cells.

To confirm this hypothesis, the efflux of Rho 123, as well as its accumulation inside the cells cultured in 2D and 2.5D, in the presence and absence of GSH, was evaluated (Figure 3). Rho 123 is a fluorescent probe that interacts with different transport proteins, but in a greater extent with the P-gp. ${ }^{[58-61,83,84]}$ The data obtained through fluorescence spectroscopy demonstrates that the efflux of Rho 123 occurs over time in all the types of MCF-7 cultures (2D and 2.5D cultures maintained in presence and absence of GSH) (Figure 3B). After $24 \mathrm{~h}$ of cells being incubated with Rho 123, 2.5 (+GSH) MCF-7 cells demonstrated $47.37 \pm 8.87 \%$ of Rho 123 efflux, while the traditional 2D cell cultures $(2 \mathrm{D}[-\mathrm{GSH}] \mathrm{MCF}-7$ cells) showed only $33.20 \pm 6.79 \%$ (Figure $3 \mathrm{~B}$ ). Furthermore, $2.5 \mathrm{D}$ MCF-7 cells cultured in the presence of GSH displayed a higher Rho 123 efflux when compared to their equivalents without GSH supplementation (Figure 3B).

To corroborate these observations, the accumulation of Rho 123 and DOX in the cellular compartments of the MCF-7 cells was assessed through CLSM images (Figure 3C,D). As expected, the lowest accumulation of the Rho 123 at 8 and $24 \mathrm{~h}$ occurred in the 2.5D(+GSH) MCF-7 cells (Figure 3C4,C8). The same profile was also observed for DOX, that is, the $2.5 \mathrm{D}(+\mathrm{GSH})$ group displayed the lowest accumulation of DOX (Figure 3D4). These results 
A

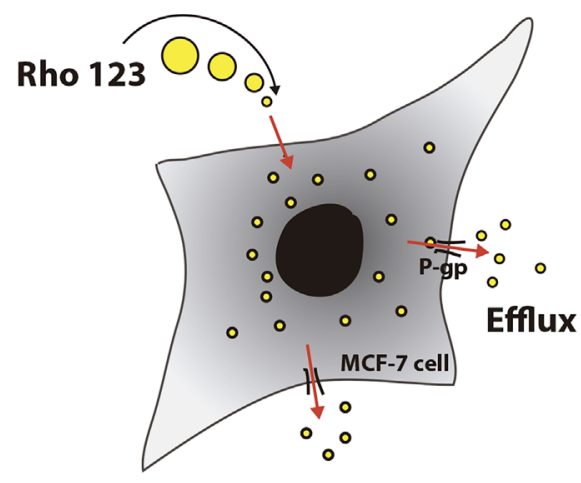

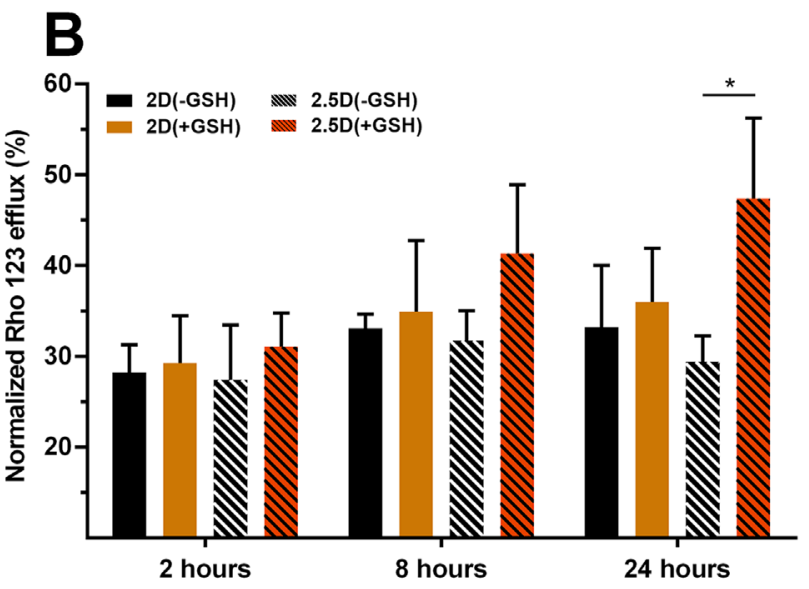

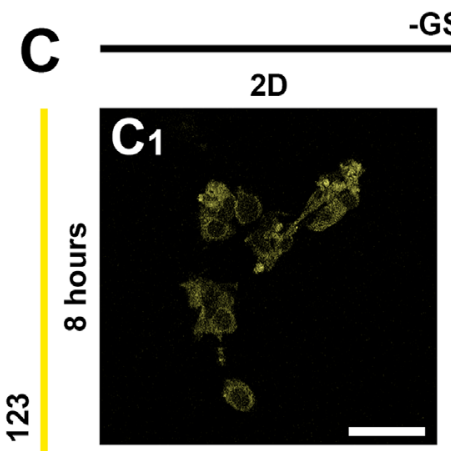

-GSH
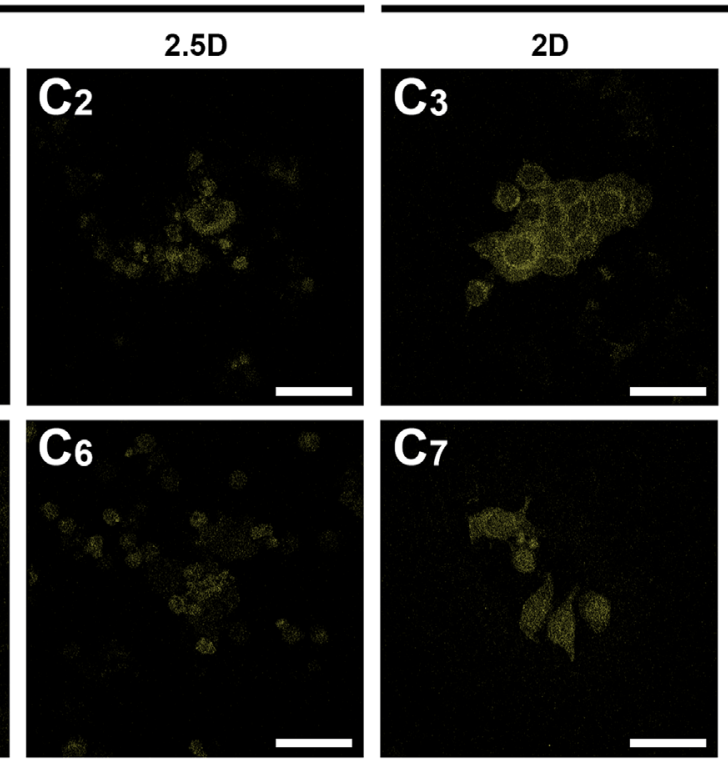

+GSH
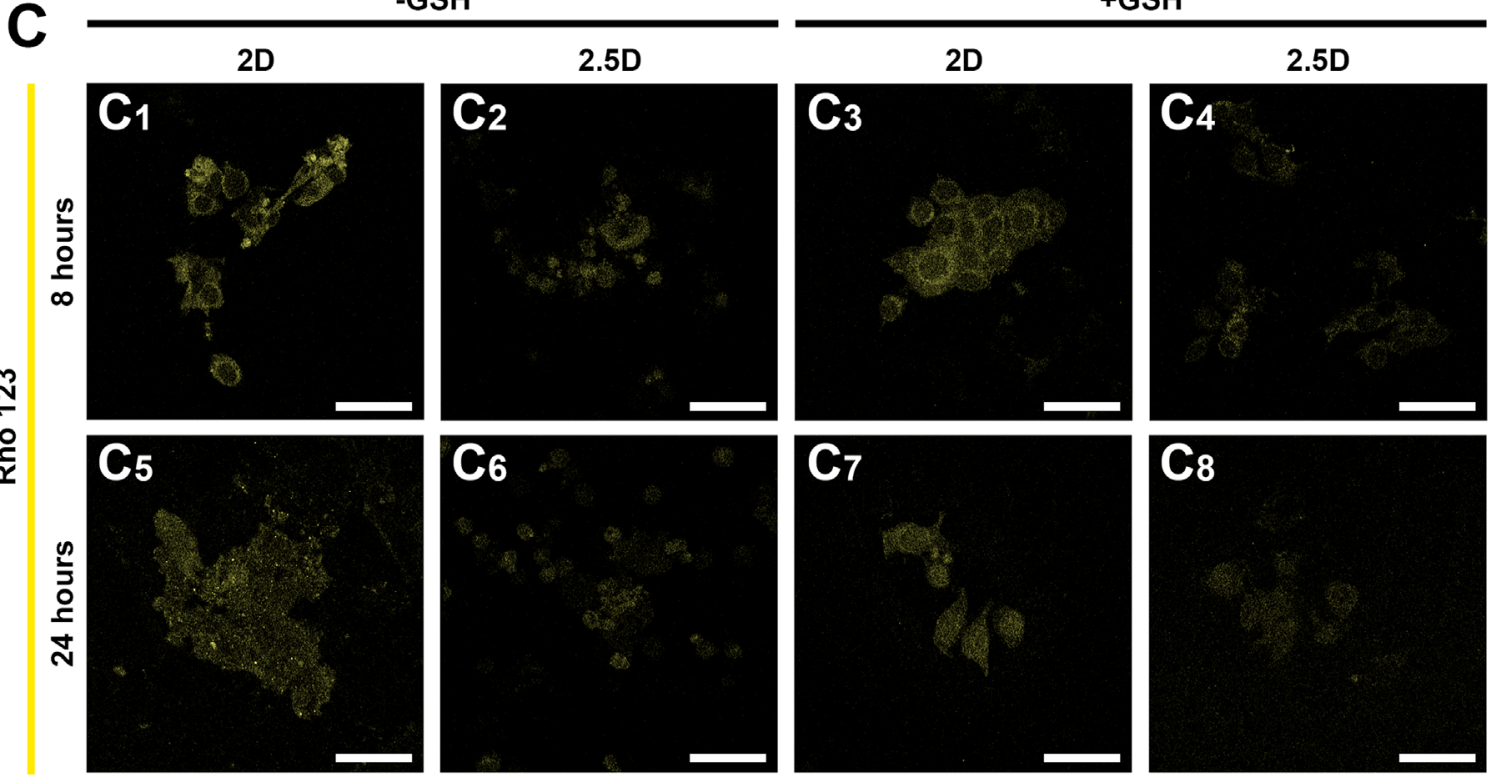

-GSH

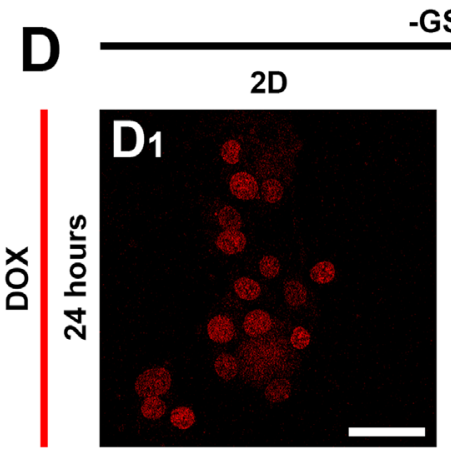

2.5D
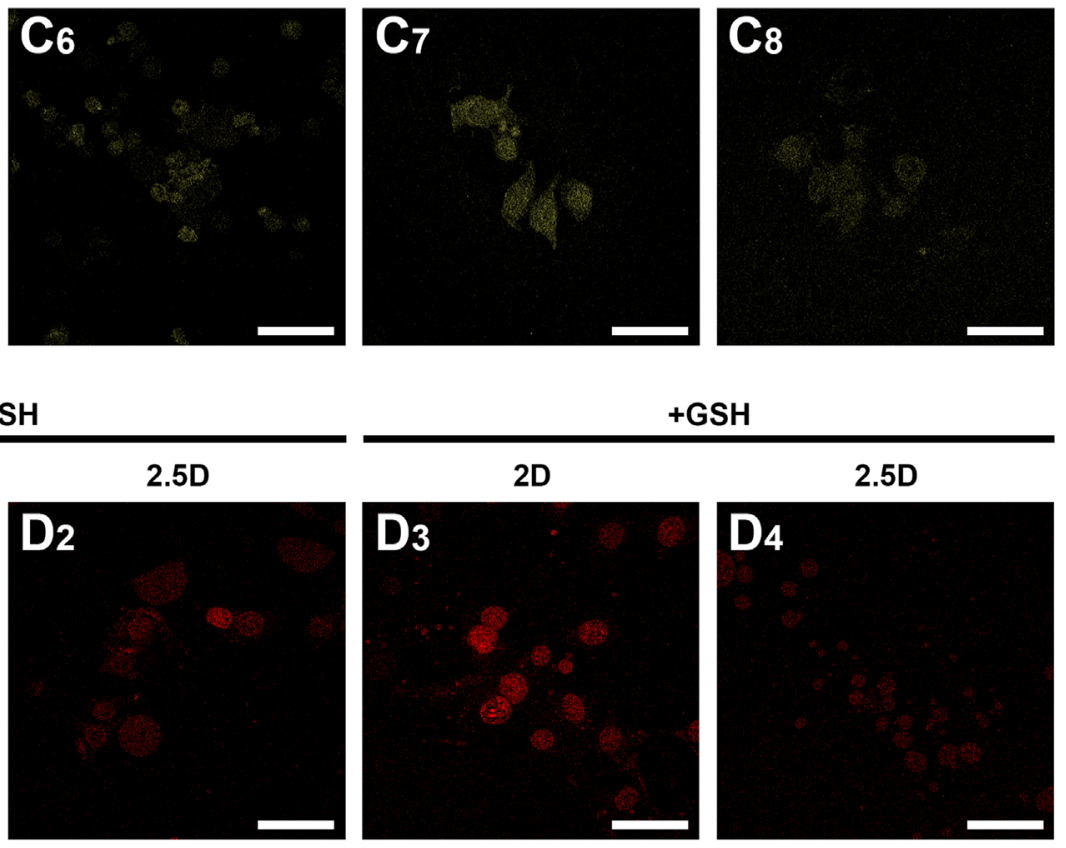

+GSH

Figure 3. Evaluation of the P-gp function in MCF-7 cells. Schematic representation of the Rho 123 efflux mechanism in MCF-7 cells (A). Normalized Rho 123 efflux in 2D $(-\mathrm{GSH}), 2 \mathrm{D}(+\mathrm{GSH}), 2.5 \mathrm{D}(-\mathrm{GSH})$, and 2.5D (+GSH) MCF-7 cells (Rho 123 efflux was quantified by fluorescence spectroscopy, $\lambda_{\text {ex }} /$ $\lambda_{\mathrm{em}}=507 / 525 \mathrm{~nm}$; values were normalized with the fluorescence intensity of the initial Rho 123 solution administrated to the cells); data are presented as mean \pm S.D. $(n=5) ;{ }^{*} P<0.05(B)$. CLSM images of the accumulation of Rho $123(C)$ and DOX (D) in $2 D(-C S H), 2 D(+G S H), 2.5 D(-G S H)$, and 2.5D (+GSH) MCF-7 cells; yellow channel: Rho $123\left(\lambda_{\mathrm{ex}} / \lambda_{\mathrm{em}}=514 / 519-650 \mathrm{~nm}\right)$; red channel: DOX $\left(\lambda_{\mathrm{ex}} / \lambda_{\mathrm{em}}=488 / 535-674 \mathrm{~nm}\right)$; scale bars correspond to $50 \mu \mathrm{m}$. 


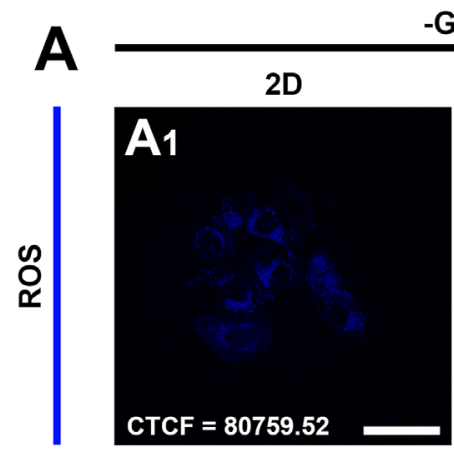

-GSH

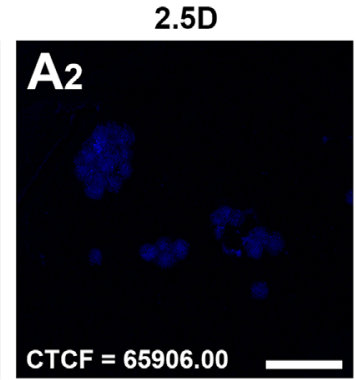

$2.5 \mathrm{D}$

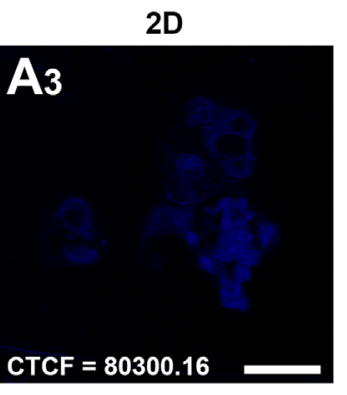

+GSH

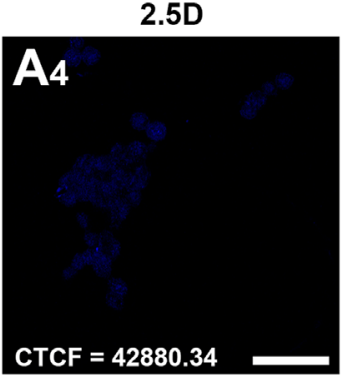

Figure 4. Evaluation of the ROS levels in MCF-7 cells. CLSM images of the ROS generation by $2 \mathrm{D}(-\mathrm{GSH}), 2 \mathrm{D}(+\mathrm{GSH}), 2.5 \mathrm{D}(-\mathrm{GSH})$, and 2.5D $(+\mathrm{GSH})$ MCF-7 cells through the $\mathrm{H}_{2}$ DCF-DA assay. Cells were grown during $24 \mathrm{~h}$, then treated with hydrogen peroxide $\left(\mathrm{H}_{2} \mathrm{O}_{2}\right)$ during 30 min before their incubation with $\mathrm{H}_{2}$ DCFDA during $1 \mathrm{~h}$. The values indicate the Corrected Total Cell Fluorescence (CTCF) measured in each image. Blue channel: $\mathrm{H}_{2}$ DCFDA oxidized (DCF) by ROS $\left(\lambda_{\mathrm{ex}} / \lambda_{\mathrm{em}}=488 / 493-599 \mathrm{~nm}\right)$; scale bars correspond to $50 \mu \mathrm{m}$.

disclose that one of the mechanisms that may be involved in $2.5 \mathrm{D}(+\mathrm{GSH})$ cells improved resistance to DOX is probably due to an increase of the P-gp activity, which is influenced by the presence of GSH as previously demonstrated in the literature. ${ }^{[7,73,82,85-88]}$ Besides, this in vitro model may also be interesting to evaluate other therapeutics that are usually explelled by the P-gp, such as Colchicine, Paclitaxe, and Vinblastinel. ${ }^{[89]}$

Moreover, the therapeutic efficacy of DOX may be limited by ROS scavengers, such as GSH. ${ }^{[90-92]}$ In fact, DOX-induced ROS production is a major mechanism of action of this drug (excessive amount of ROS causes oxidative damage to lipids, proteins and DNA, ${ }^{[88]}$ and leads to the activation of signaling pathways involved in cancer cells apoptosis). ${ }^{[73,88,93,94]}$ As an antioxidant, GSH stabilizes the redox state of the cells by ROS scavenging, as previously discussed. ${ }^{[88,95-99]}$ A study performed by Armstrong et al. demonstrated that the treatment of cells with BSO (inhibitor of GSH synthesis) resulted in an early decline in cellular GSH, followed by an increase of ROS levels, which further led to the induction of various apoptotic signals. ${ }^{[45]}$ In a more recent study, it was demonstrated that the treatment of T47D breast cancer cells with BSO/DOX drug combination reduced more the cancer cells' survival than the single administration of DOX, since the BSO (inhibitor of GSH synthesis) acts synergistically with DOX to produce oxidative stress (e.g., ROS production). ${ }^{[100]}$ Therefore, $\mathrm{H}_{2}$ DCFDA cellular ROS detection assay was performed to elucidate if $\mathrm{GSH}$ influenced the $2.5 \mathrm{D}(+\mathrm{GSH})$ MCF-7 cells resistance to DOX by decreasing the ROS levels in these cells (Figure 4). In this type of assay, greater fluorescence signals in the cells are directly correlated with a higher presence of ROS. According to the CLSM analysis, the $2.5 \mathrm{D}(+\mathrm{GSH}) \mathrm{MCF}-7$ cells displayed a weaker fluorescence intensity ( $\mathrm{CTCF}=42880.34)$, when compared to $2 \mathrm{D}(-\mathrm{GSH}), 2 \mathrm{D}(+\mathrm{GSH})$, and $2.5 \mathrm{D}(-\mathrm{GSH}) \mathrm{MCF}-7$ cell cultures $(\mathrm{CTCF}=80759.52,80300.16$, and 65906.00, respectively) (Figure 4). This indicates that ROS levels are lower in the 2.5D $(+\mathrm{GSH})$ model, probably due to its higher ROS scavenging capacity. Therefore, decreased ROS levels may be another mechanism that is responsible for the resistance of $2.5 \mathrm{D}(+\mathrm{GSH})$ cells to DOX. Additionally, this model may also be useful for the analysis of other ROS-dependent therapeutics, such as Bleomycin, Cisplatin and Diclofenac. ${ }^{[101,102]}$

\section{Conclusion}

Resistant 2D cell cultures can closely mimic the drug resistance profile presented by the in vivo tumors. In this study, it was demonstrated that a DOX-resistant 2D cell culture model can be obtained in a short-period by collecting the cells obtained from dissociated 10 days-old spheroids and by culturing these cells in medium supplemented with GSH $(2.5 \mathrm{D}[+\mathrm{GSH}] \mathrm{MCF}-7$ cell cultures). This in vitro model displays a drug resistance profile to DOX closer to that displayed by 3D spheroids, and higher than that obtained in 2D cell cultures. Results also showed that the resistance of $2.5 \mathrm{D}(+\mathrm{GSH}) \mathrm{MCF}-7$ cells may be associated with its increased P-gp function and ROS scavenging levels. Overall, this study demonstrates that resistant 2D MCF-7 cell cultures can be a promising tool for drug screening aimed for breast cancer treatment, since this model is compatible with the methodologies and techniques that are already used for the analysis of conventional 2D in vitro assays.

\begin{abstract}
Abbreviations
$\gamma$-GCS, $\gamma$-Glutamylcysteine synthetase; ADR, adriamycins; BSO, buthionine sulfoximine; CLSM, Confocal Laser Scanning Microscopy; DCF, 2', 7'dichlorofluorescein; DMEM-F12, Dulbecco's Modified Eagle's medium F12; DOX, doxorubicin; EDTA, ethylenediaminetetraacetic acid; FBS, fetal bovine serum; $\mathrm{GSH}$, glutathione; $\mathrm{H}_{2}$ DCFDA, 2',7'-dichlorofluorescein diacetate; HTS, High-Throughput Drug Screening; $I_{50}, 50 \%$ inhibitory concentration; $\mathrm{K}^{-}$, negative control; MCF-7, estrogen-dependent human breast adenocarcinoma; PFA, P-glycoprotein; P-gp, paraformaldehyde; PBS, phosphate-buffered saline solution; ROS, reactive oxygen species; Rho 123, rhodamine 123; S.D., standard deviation.
\end{abstract}

\section{Supporting Information}

Supporting Information is available from the Wiley Online Library or from the author.

\section{Acknowledgements}

This work was supported by FEDER funds through the POCI - COMPETE 2020 - Operational Programme Competitiveness and Internationalisation 
in Axis I - Strengthening research, technological development and innovation (Project POCl-01-0145-FEDER-007491) and National Funds by FCT - Foundation for Science and Technology (Project UID/Multi /00709/2013). The funding from CENTRO-01-0145-FEDER-028989 is also acknowledged. Elisabete C. Costa and Duarte de Melo-Diogo acknowledge for their grants: SFRH/BD/103507/2014 and SFRH/BD/103506/ 2014 , respectively. The funders had no role in the decision to publish or in the preparation of the manuscript.

\section{Conflict of Interest}

The authors declare no commercial or financial conflict of interest.

\section{Keywords}

2D cell cultures, breast cancer, doxorubicin, drug resistance, glutathione, spheroids

Received: May 22, 2018

Revised: September 14, 2018

Published online: October 10, 2018

[1] L. A. Torre, F. Bray, R. L. Siegel, J. Ferlay, J. Lortet-Tieulent, A. Jemal, CA Cancer J. Clin. 2015, 65, 87.

[2] S. Singh, B. Sharma, S. S. Kanwar, A. Kumar, Front. Plant Sci. 2016, 7, 1667.

[3] Y. Luqmani, Med. Princ. Pract. 2005, 14, 35.

[4] G. Bradley, V. Ling, Cancer Metastasis Rev. 1994, 13, 223.

[5] R. Callaghan, F. Luk, M. Bebawy, Drug Metab. Dispos. 2014, 42, 623.

[6] S. Breslin, L. O'Driscoll, Drug Discov. Today 2013, 18, 240.

[7] V. Koshkin, L. E. Ailles, G. Liu, S. N. Krylov, J. Cell. Biochem. 2017, 118,154

[8] D. Zips, H. D. Thames, M. Baumann, In Vivo 2005, $19,1$.

[9] N. Cook, D. I. Jodrell, D. A. Tuveson, Drug Discov. Today 2012, 17, 253.

[10] N. Niu, L. Wang, Pharmacogenomics 2015, 16, 273.

[11] L. B. Weiswald, D. Bellet, V. Dangles-Marie, Neoplasia 2015, 17, 1.

[12] D. van den Brand, L. F. Massuger, R. Brock, Bioconjugate Chem. 2017, 28, 846.

[13] K. Duval, H. Grover, L. H. Han, Y. Mou, A. F. Pegoraro, J. Fredberg, Z. Chen, Physiology 2017, 32, 266.

[14] E. C. Costa, A. F. Moreira, D. de Melo-Diogo, V. M. Gaspar, M. P. Carvalho, I. J. Correia, Biotechnol. Adv. 2016, 34, 1427.

[15] T. C. Tseng, C. W. Wong, F. Y. Hsieh, S. h. Hsu, Biotechnol. J. 2017, $12,1700064$.

[16] R. Edmondson, J. J. Broglie, A. F. Adcock, L. Yang, Assay Drug Dev. Technol. 2014, 12, 207.

[17] S. Doublier, D. C. Belisario, M. Polimeni, L. Annaratone, C. Riganti, E. Allia, D. Ghigo, A. Bosia, A. Sapino, BMC Cancer 2012, 12, 4.

[18] K. Chitcholtan, P. H. Sykes, J. J. Evans, J. Transl. Med. 2012, 10, 38.

[19] M. Peng, J. Wang, Y. Yi, Y. Liu, X. Qi, Transl. Cancer Res. 2017, 5, S1402.

[20] C. Bingel, E. Koeneke, J. Ridinger, A. Bittmann, M. Sill, H. Peterziel, J. K. Wrobel, I. Rettig, T. Milde, U. Fernekorn, F. Weise, A. Schober, O. Witt, I. Oehme, Cell Death Dis. 2017, 8, e3013.

[21] J. Sarkar, J. Kumari, J. M. Tonello, M. Kamihira, A. Kumar, Biotechnol. J. 2017, 12, 1700274.

[22] J. A. Hickman, R. Graeser, R. de Hoogt, S. Vidic, C. Brito, M. Gutekunst, H. van der Kuip, Biotechnol. J. 2014, 9, 1115.

[23] Y. Fang, R. M. Eglen, SLAS Discov. 2017, 22, 456.

[24] S. A. Langhans, Front. Pharmacol. 2018, 9, 6.
[25] S. I. Montanez-Sauri, D. J. Beebe, K. E. Sung, Cell. Mol. Life Sci. 2015, 72, 237.

[26] M. Rimann, U. Graf-Hausner, Curr. Opin. Biotechnol. 2012, 23, 803.

[27] S.-L. Ryan, A.-M. Baird, G. Vaz, A. J. Urquhart, H. Senge, D. J. Richard, K. J. O'Byrne, A. M. Davies, Assay Drug Dev. Technol. 2016, 14, 19.

[28] M. Zanoni, F. Piccinini, C. Arienti, A. Zamagni, S. Santi, R. Polico, A. Bevilacqua, A. Tesei, Sci. Rep. 2016, 6, 19103.

[29] W. Asghar, R. El Assal, H. Shafiee, S. Pitteri, R. Paulmurugan, U. Demirci, Mater. Today 2015, 18, 539.

[30] E. C. Costa, D. de Melo-Diogo, A. F. Moreira, M. P. Carvalho, I. J. Correia, Biotechnol. J. 2017, 13, 1.

[31] T. Nishikawa, Y. Tanaka, K. Kusamori, N. Mizuno, Y. Mizukami, Y. Ogino, K. Shimizu, S. Konishi, Y. Takahashi, Y. Takakura, Biotechnol. J. 2017, 12, 1600513.

[32] A. Walzl, C. Unger, N. Kramer, D. Unterleuthner, M. Scherzer, M. Hengstschläger, D. Schwanzer-Pfeiffer, H. Dolznig, J. Biomol. Screening 2014, 19, 1047.

[33] P. J. Lou, P. S. Lai, M. J. Shieh, A. J. Macrobert, K. Berg, S. G. Bown, Int. J. Cancer 2006, 119, 2692.

[34] S. AbuHammad, M. Zihlif, Genomics 2013, 101, 213.

[35] B. D. Lopez-Ayllon, V. Moncho-Amor, A. Abarrategi, I. I. de Cáceres, J. Castro-Carpeño, C. Belda-Iniesta, R. Perona, L. Sastre, Cancer Med. 2014, 3, 1099.

[36] S. Desrini, E. N. Sholikhah, Bangladesh J. Med. Sci. 2017, 16, 91.

[37] H. Feda'H, M. A. Zihlif, Genomics 2014, 104, 477.

[38] Y. Qin, J. Roszik, C. Chattopadhyay, Y. Hashimoto, C. Liu, Z. A. Cooper, J. A. Wargo, P. Hwu, S. Ekmekcioglu, E. A. Grimm, Mol. Cancer Ther. 2016, 15, 1.

[39] L. Schito, G. L. Semenza, Trends Cancer 2016, 2, 758.

[40] W.-L. Liao, S.-C. Lin, H. S. Sun, S.-J. Tsai, Biomarkers Genomic Med. 2014, 6, 1.

[41] J. M. Estrela, A. Ortega, E. Obrador, Crit. Rev. Clin. Lab. Sci. 2006, 43, 143.

[42] N. Traverso, R. Ricciarelli, M. Nitti, B. Marengo, A. L. Furfaro, M. A. Pronzato, U. M. Marinari, C. Domenicotti, Oxid. Med. Cell. Longevity 2013, 2013, 972913.

[43] H. Hong, Y. Lu, Z. N. Ji, G. Q. Liu, J. Neurochem. 2006, 98, 1465.

[44] C. Kerksick, D. Willoughby, J. Int. Soc. Sports Nutr. 2005, 2, 38.

[45] J. S. Armstrong, K. K. Steinauer, B. Hornung, J. M. Irish, P. Lecane, G. W. Birrell, D. M. Peehl, S. J. Knox, Cell Death Differ. 2002, 9, 252.

[46] Y. H. Han, S. Z. Kim, S. H. Kim, W. H. Park, Drug Chem. Toxicol. 2010, 33, 403

[47] M. J. Ruiz-Gomez, A. Souviron, M. Martinez-Morillo, L. Gil, J. Physiol. Biochem. 2000, 56, 307.

[48] A. Angelini, C. Di llio, M. L. Castellani, P. Conti, F. Cuccurullo, J. Biol. Regul. Homeostatic Agents 2010, 24, 197.

[49] M. P. Gamcsik, M. S. Kasibhatla, S. D. Teeter, O. M. Colvin, Biomarkers 2012, 17, 671.

[50] C. F. Thorn, C. Oshiro, S. Marsh, T. Hernandez-Boussard, H. McLeod, T. E. Klein, R. B. Altman, Pharmacogenet. Genomics 2011, 21, 440.

[51] L. Smith, M. B. Watson, S. L. O'Kane, P. J. Drew, M. J. Lind, L. Cawkwell, Mol. Cancer Ther. 2006, 5, 2115.

[52] E. C. Costa, V. M. Gaspar, J. G. Marques, P. Coutinho, I. J. Correia, PLOS ONE 2013, 8, e70072.

[53] E. C. Costa, A. F. Moreira, D. de Melo-Diogo, I. J. Correia, J. Biomed. Opt. 2018, 23, 1.

[54] E. C. Costa, V. M. Gaspar, P. Coutinho, I. J. Correia, Biotechnol. Bioeng. 2014, 111, 1672.

[55] M. P. Carvalho, E. C. Costa, I. J. Correia, Biotechnol. Prog. 2017, 33, 1346.

[56] D. de Melo-Diogo, V. M. Gaspar, E. C. Costa, A. F. Moreira, D. Oppolzer, E. Gallardo, I. J. Correia, Eur.J. Pharm. Biopharm. 2014, 88,718 . 
[57] J. G. Marques, V. M. Gaspar, D. Markl, E. C. Costa, E. Gallardo, I. J. Correia, Pharm. Res. 2014, 31, 2516.

[58] D. L. Liu, Y. J. Li, D. H. Yang, C. R. Wang, J. Xu, N. Yao, X. Q. Zhang, Z. S. Chen, W. C. Ye, D. M. Zhang, Int. J. Oncol. 2015, 46, 2029.

[59] S. P. Hämmerle, B. Rothen-Rutishauser, S. D. Krämer, M. Günthert, H. Wunderli-Allenspach, Eur. J. Pharm. Sci. 2000, 12, 69.

[60] T. H. Kim, Y. J. Shin, A. J. Won, B. M. Lee, W. S. Choi, J. H. Jung, H. Y. Chung, H. S. Kim, Biochim. Biophys. Acta 2014, 1840, 615.

[61] F. Shen, S. Chu, A. K. Bence, B. Bailey, X. Xue, P. A. Erickson, M. H. Montrose, W. T. Beck, L. C. Erickson, J. Pharmacol. Exp. Ther. 2008, 324, 95.

[62] C. Pais-Silva, D. de Melo-Diogo, I. J. Correia, Eur. J. Pharm. Biopharm. 2017, 113, 108.

[63] E. C. Costa, A. F. Moreira, D. de Melo-Diogo, I. J. Correia, Opt. Laser Technol. 2018, 106, 94.

[64] P. Klaka, S. Grüdl, B. Banowski, M. Giesen, A. Sättler, P. Proksch, T. Welss, T. Förster, PLoS ONE 2017, 12, e0182752.

[65] W. Ke, P. Yu, J. Wang, R. Wang, C. Guo, L. Zhou, C. Li, K. Li, Med. Oncol. 2011, 28, 135.

[66] B. G. Zhou, C. S. Wei, S. Zhang, Z. Zhang, H. m. Gao, J. Cell. Biochem. 2018, 119, 3885.

[67] M. Han, Q. Lv, X.-J. Tang, Y.-L. Hu, D.-H. Xu, F.-Z. Li, W.-Q. Liang, J.Q. Gao, J. Controlled Release 2012, 163, 136.

[68] U. De, P. Chun, W. S. Choi, B. M. Lee, N. D. Kim, H. R. Moon, J. H. Jung, H. S. Kim, Int. J. Oncol. 2014, 44, 167.

[69] M. Ye, Y. Han, J. Tang, Y. Piao, X. Liu, Z. Zhou, J. Gao, J. Rao, Y. Shen, Adv. Mater. 2017, 29, 1702342.

[70] C. Y. Ang, S. Y. Tan, Y. Zhao, Org. Biomol. Chem. 2014, 12, 4776.

[71] L. Guo, Y. Zhou, S. Wang, Y. Wu, J. Cell. Mol. Med. 2014, 18, 2009.

[72] R. R. Perry, J. Mazetta, M. Levin, S. C. Barranco, Cancer 1993, 72, 783.

[73] A. L. Ortega, S. Mena, J. M. Estrela, Cancers 2011, 3, 1285.

[74] X. Wang, X. Zhen, J. Wang, J. Zhang, W. Wu, X. Jiang, Biomaterials 2013, 34, 4667.

[75] A. F. Moreira, D. R. Dias, E. C. Costa, I. J. Correia, Eur. J. Pharm. Sci. 2017, 104, 42.

[76] F. Hirschhaeuser, H. Menne, C. Dittfeld, J. West, W. Mueller-Klieser, L. A. Kunz-Schughart, J. Biotechnol. 2010, 148, 3.

[77] L. A. Kunz-Schughart, J. P. Freyer, F. Hofstaedter, R. Ebner, J. Biomol. Screening 2004, 9, 273.

[78] C. Bai, M. Yang, Z. Fan, S. Li, T. Gao, Z. Fang, J. Exp. Clin. Cancer Res. 2015, 34, 1.

[79] S.-Y. Jeong, J.-H. Lee, Y. Shin, S. Chung, H.-J. Kuh, PLoS ONE 2016, 11, e0159013.

[80] C. J. Lovitt, T. B. Shelper, V. M. Avery, BMC Cancer 2018, 18, 41.
[81] S. Harmsen, I. Meijerman, C. Febus, R. Maas-Bakker, J. Beijnen, J. Schellens, Cancer Chemother. Pharmacol. 2010, 66, 765.

[82] G. Zaman, J. Lankelma, O. Van Tellingen, J. Beijnen, H. Dekker, C. Paulusma, R. O. Elferink, F. Baas, P. Borst, Proc. Natl. Acad. Sci. 1995, 92, 7690.

[83] Y. Wang, D. Hao, W. D. Stein, L. Yang, Biochim. Biophys. Acta 2006, $1758,1671$.

[84] C. Saengkhae, C. Loetchutinat, A. Garnier-Suillerot, Biophys. J. 2003, 85, 2006.

[85] A. Angelini, C. I. Di, M. Castellani, P. Conti, F. Cuccurullo, J. Biol. Regul. Homeostatic Agents 2010, 24, 197.

[86] M. O'brien, K. Tew, Eur. J. Cancer 1996, 32, 967.

[87] D. W. Loe, K. C. Almquist, R. G. Deeley, S. P. Cole, J. Biol. Chem. 1996, 271, 9675.

[88] D. Trachootham, J. Alexandre, P. Huang, Nat. Rev. Drug Discovery 2009, 8, 579.

[89] Y.-J. Wang, Y.-K. Zhang, R. J. Kathawala, Z.-S. Chen, Cancers 2014, 6, 1925.

[90] S. C. Nunes, J. Serpa, Int. J. Mol. Sci. 2018, 19, e 1882.

[91] S. Dey, A. Sidor, B. O'Rourke, J. Biol. Chem. 2016, 291, 11185.

[92] X. Leng, H. Jia, X. Sun, L. Shangguan, Q. Mu, B. Wang, J. Fang, Sci. Rep. 2015, 5, 17749.

[93] O. Tacar, P. Sriamornsak, C. R. Dass, J. Pharm. Pharmacol. 2013, 65, 157.

[94] D. Cappetta, A. De Angelis, L. Sapio, L. Prezioso, M. Illiano, F. Quaini, F. Rossi, L. Berrino, S. Naviglio, K. Urbanek, Oxid. Med. Cell. Longevity 2017, 2017, 1521020.

[95] S. Lee, D. Pagoria, A. Raigrodski, W. Geurtsen, J. Biomed. Mater. Res. B Appl. Biomater. 2007, 83, 391.

[96] J. Kengen, J.-P. Deglasse, M.-A. Neveu, L. Mignion, C. Desmet, F. Gourgue, J.-C. Jonas, B. Gallez, B. F. Jordan, Free Radical Res. 2018, 52, 256.

[97] D. J. Garama, T. J. Harris, C. L. White, F. J. Rossello, M. Abdul-Hay, D. J. Gough, D. E. Levy, Mol. Cell. Biol. 2015, 35, 3646.

[98] J. Wilke, T. Kawamura, N. Watanabe, H. Osada, S. Ziegler, H. Waldmann, Bioorg. Med. Chem. 2018, 26, 1453.

[99] T. Miran, A. T. Vogg, N. Drude, F. M. Mottaghy, A. Morgenroth, FASEB J. 2018, 32, 2803.

[100] E. H. Mustafa, H. T. Mahmoud, M. Y. Al-Hudhud, I. Ahmad, S. Yasin, A. Elkarmi, L. Tahtamouni, Asian Pac. J. Cancer Prev. 2015, 16, 3213.

[101] D. Ivanova, Z. Zhelev, I. Aoki, R. Bakalova, T. Higashi, Chin. J. Cancer Res. 2016, 28, 383.

[102] D. G. Deavall, E. A. Martin, J. M. Horner, R. Roberts, J. Toxicol. 2012, 2012, 645460. 